value of shear stress required to produce movement along a fault (Fig. 2).

The results of the Challenger 'flow-out' indicate that the large overthrusts of older sediment over newly scraped-off oceanic sediments landward of trenches occur along fault zones 'lubricated' by excess pore pressures. The Challenger also turned up evidence for the mode of origin of these overpressures. Temperature measurements made at depths of 50 to more than $150 \mathrm{~m}$ into the sediment above the fault zone gave values closely grouped at 14 to $16^{\circ} \mathrm{C}$. These values are unusual in two respects: the temperatures from 50 to $150 \mathrm{~m}$ sub-bottom are virtually isothermal instead of increasing uniformly with depth and they are much hotter than the more typical 5 to $10^{\circ} \mathrm{C}$ for such tectonic settings.
Upward advection of warm pore fluids through a highly permeable sedimentary section is implied. The origin of this advecting water is likely to be the oceanic sedimentary section being squeezed during the subduction event. The newly released water not only advects upwards but also causes abnormal overpressures, allowing overthrusting to occur along well lubricated fault zones.

Finally, it is sobering to find the explanation of so fundamental a plate tectonic process in the literature of a previous time. Hubbert and Rubey (1959) themselves trace the origins of their solution to the problem back to the mid 1920 s, and the field evidence for overthrusting began to accumulate even as early as the 1840 s.

\title{
Do radon anomalies predict earthquakes?
}

\section{from Chi-Yu King}

THE discovery that the radon content of groundwater in a deep well increased significantly before the magnitude 5.3 Tashkent earthquake in 1966 has prompted many research groups in the USSR, China, Japan and the US to monitor radon levels in wells and springs in earthquake-prone zones. Many radon anomalies have now been recorded, especially in Russia and China, and some are thought to be related and precursory to earthquakes as far away as several hundred kilometres ${ }^{2,3}$. Such claims have often met with scepticism, particularly in the United States because no known mechanism could explain the relationship. Recently, a US research group reported a similar finding in southern California, a region considered to be a major seismic gap, where a long segment of the San Andreas fault was broken during a magnitude 8 earthquake in 1857 and where recent episodes of aseismic crustal uplift have been hotly debated ${ }^{4}$.

Shapiro and his colleagues at the California Institute of Technology reported $^{5}$ that during the second half of 1979, anomalously high radon emanation was recorded at two of their three monitoring stations spaced about $30 \mathrm{~km}$ apart along an east-west frontal fault system of the Transverse Ranges of southern California. They suggested that the radon anomalies, together with several other anomalies recorded at about the

Chi-Yu King is a geophysicist at the US Geological Survey Officer of Earthquake Studies, Menlo Park, California. same time in and near the Transverse Ranges by other investigators, may be the result of large-scale strain and that they may have been precursory to a magnitude 6.6 earthquake on 15 October 1979 , in the Imperial Valley, which is about $290 \mathrm{~km}$ to the south-east of the radon stations.

Shapiro also cites anomalies observed $20 \mathrm{~km}$ east of his eastern station at Arrowhead Hot Springs by Craig and coworkers $^{6}$ of the Scripps Institution of Oceanography. The group took monthly water samples from Arrowhead and 15 other springs and thermal wells scattered throughout southern California between the Transverse Ranges and Imperial Valley. They analysed the contents of radon, helium and several other dissolved gases and found the values at Arrowhead to have increased significantly between May and the end of 1979 . They attributed these increases to a smaller (magnitude 4.8 ) but closer $(30 \mathrm{~km})$ earthquake that occurred on 30 June at Big Bear Lake. No significant anomaly was recorded at any of the other 15 sites during this period.

A third group studying groundwater radon in southern California is headed by Teng ${ }^{7}$, of the University of Southern California. He analysed water samples taken once a week from 13 wells and springs in the Transverse Ranges. One of the study sites was Arrowhead Hot Springs, about $150 \mathrm{~m}$ from Craig's site, and a sudden increase in radon emanation was detected in May 1979. However, not enough data were collected at Arrowhead to see how long the radon anomaly lasted. Teng and colleagues detected, in addition, some spiky radon increases at two other sites about 10 and $50 \mathrm{~km}$, respectively, north-west of Arrowhead, and they consider the anomalies at all three sites to be precursory to the Big Bear earthquake.

Previously, radon anomalies had been observed before the magnitude 5.0 Malibu earthquake on 1 January 1979, at one of Teng's sites in the Malibu Mountains and at Shapiro's western station about $54 \mathrm{~km}$ east of the epicentre. However, no significant anomaly was observed before some other significant southern California earthquakes, notably the magnitude 5.6 Santa Barbara earthquake on 13 August 1978 , about $150 \mathrm{~km}$ west of Shapiro's western station.

The recent radon data from southern California (like those from USSR, Japan and China), although encouraging, leave many questions unanswered, even if we assume that the anomalies are truly earthquake related and not merely coincidental. For example, why are some earthquakes preceded by radon anomalies and others not? Why have the 1979 anomalies been recorded mainly at scattered places in the Transverse Ranges, where no earthquake of magnitude larger than 5.0 occurred, yet in Imperial Valley, the site of the largest earthquake, no anomaly other than a 15-week drop in seismicity was recorded? If anomalies are site dependent, what factors distinguish a good site from a bad one? One might also ask whether the empirical relationships given in the literature between the amplitude, duration and spatial extent of the anomalies and the magnitude, time and location of the ensuing earthquakes are valid or oversimplified, why some radon anomalies are episodic, but others spiky, and why most anomalies are positive, yet a few negative (decrease from background level). Finally, what are the mechanisms that relate radon levels and earthquake activities?

Clearly more data on radon, as well as on other geochemical and geophysical parameters, are needed. During a recent trip to China, I was told that hydrogeochemical studies were accorded the third priority in the Chinese earthquake prediction programme, after seismicity and crustal deformation studies. Research is progressing rapidly in the United States and nearly 30 pertinent papers have been published during the past 2 years, most of them in two special issues of the Journal of Geophysical Research (June 1980) and the Geophysical Research Letters (May 1981).

\footnotetext{
1. Ulomov, V.I. \& Mavashev, B.Z. Dokl. Akad. Nauk SSSR, Earth Sci. Sec., 174, 9 (1968)

2. Sultankhodzhayev, A.N. Chernov, I.G. \& Zakirov, T. Dokl. Akad. Nauk uzbek. SSSR, No. 7, 51 (1976).

3. Jiang, F. \& Li, G. Geophys. Res. Lett. 8, 469 (1981)

4. Castle, R.O. et al. Science 213, 246 (1981).

5. Shaprio, M.H. et al. J. geophys. Res. 86, 1725 (1981).

6. Craig, H., Chung, Y., Poreda, R., Lupton, J. \& Damasceno, S. EOS Trans. Am. Geophys. Union 61. 1035 (1980).

Teng, T., Sun, L. \& McRaney, J.K. Geophys. Res. Lett. 8, 441 (1981).
} 